\title{
PERBANDINGAN PUISI DOAKARYA AMIR HAMZAH DAN DOA KARYA SANUSI PANE
}

\author{
Cindy Geofany \\ Deby Triananda \\ Erlinda Sari E. \\ Universitas Muhammadiyah Malang
}

\begin{abstract}
Abstrak
Penelitian ini mendeskripsikan tentang perbandingan puisi Doa karya Amir Hamzah dan Sanusi Pane. Tujuan dari penelitian ini adalah mendeskripsikan persamaan aspek-aspek religius pada puisi Doa karya Amir Hamzah dan puisi Doa karya Sanusi Pane. Penelitian ini menggunakan metode analisis isi yang sumber datanya diperoleh dari puisi Doa dengan menggunakan pendektan sastra bandingan yang berfokus pada teori Hutomo.Hasil dari penenlitian ini adalah adanya hubungan persamaan dengan puisi Doa karya Amir Hamzah dan Sanusi Pane. Persamaan tersebut dapat dilihat dari gaya penulisan, judul, makna, dan kedua penyair tersebut juga sama-sama menyebut Tuhan dengan sebutan kekasih.
\end{abstract}

KataKunci: perbandingan, puisi, doa

\section{PENDAHULUAN}

Membicarakan sastra dan keagamaan berarti mempertautkan pengaruh agama dalam sebuah karya, atau adanya suatu karya sastra yang bernafaskan agama. Sastra keagamaan menarik untuk dijadikan objek penelitian karena terdapat kaitan erat antara karya sastra dan agama, sastra tumbuh dari sesuatu yang bersifat religius, sebagaimana dikatakan oleh Mangunwijaya bahwa pada awal mulanya, segala sastra itu adalah religius (Mangunwijaya, 1982:11).
Istilah religius membawa konotasi pada makna agama, religius dan agama memang erat berkaitan, berdampingan, bahkan dapat melebur dalam satu kesatuan, namun sebenarnya keduanya menyiratkan pada makna yang berbeda (Nurgiyantoro,2002: 326-327).

Agama lebih menunjukkan pada kelembagaan kebaktian kepada Tuhan dan biasanya terbatas pada ajaran-ajaran dan peraturanperaturan (Atmosuwito, 1998: 123). Religius lebih melihat dari aspek yang di dalam lubuk hati, riak 
getaran nurani pribadi, totalitas kedalaman pribadi manusia. Dengan demikian, religius bersifat mengatasi lebih dalam dan lebih luas dari agama yang tampak formal dan resmi (Mangunwijaya, 1982:11-12).

\section{Religius dalam Kamus Besar} Bahasa Indonesia, berarti bersifat religi atau bersifat keagamaan (KBBI, 2002:944). Disini yang dimaksud dengan perasaan keagamaan ialah segala perasaan batin yang ada hubungannya dengan Tuhan. Seperti perasaan dosa, perasaan takut, dan kebesaran Tuhan (Atmosuwito, 1998:124).

Menilai sebuah karya yang bertema keagamaan, dapat dilihat tema dan persoalannya dengan Islam, jika semakin dekat tema dan persoalannya dengan Islam, maka semakin kukuhlah nilai Islam dalam sebuah karya tersebut (Husin,1995: 142).

Karya sastra sejatinya merupakan suatu gagasan dalam tulisan yang terkait dengan karya-karya sastra yang lainnya. Pada hakikatnya karya sastra merupakan karya yang tidak seutuhnya murni, melainkan abstrak. Maka dari itu, suatu teks tidak dapat dipahami hanya dengan satu teks saja, melainkan membutuhkan teksteks lain yang berkaitan. Seringkali sebuah karya berlatarkan pada karya sastra yang lain, baik menentang atau meneruskan karya sastra yang menjadi latar itu (Pradopo, 2009: 112).

Sastra bandingan merupakan salah satu dari sekian banyak pendekatan yang ada dalam ilmu sastra. Sastra bandingan Pada awalnya adalah membandingkan karya sastra dengan karya sastra, untuk mencari kefavoritan dan keoriginalitasan karya. Perbandingan ituakan ditemukan karya-karya yang bertaraf nasional dan bahkan bertaraf internasional(Endraswara, 2008:130).

Sastra bandingan juga tidak terpatok pada karya-karya besar walaupun kajian sastra bandingan sering kali berkenaan dengan penulis-penulis ternama yang mewakili suatu zaman. Kajian penulis baru yang belum mendapat pengakuan dunia pun dapat digolongkan dalam sastra bandingan. Batasan sastra bandingan tersebut menunjukkan bahwa perbandingan tidak hanya terbatas pada sastra antar 
bangsa, tetapi juga sesama bangsa sendiri, misalnya antar pengarang Antar genetik, antar zaman, antar bentuk, dan antar tema.

Pusi yang akan kita kaji merupakan puisi karya Amir Hamzah dan Sanusi Pane yang berjudul Doa,kedua puisi tersebut memilikibeberapa

persamaandiantaranya jika ditinjau dari segi judul, gaya penulisan, makna, dan sebutannya untuk tuhan.

Berdasarkan uraian diatas, masalah dalam penelitian ini adalah bagaimana persamaan yang terdapat pada puisi Doa karya Amir Hamzah dan puisi Doa karya Sanusi Pane? Tujuan dari penelitian ini adalah mendeskripsikan persamaan aspekaspek religius pada puisi Doa karya Amir Hamzah dan puisi Doa karya Sanusi Pane.

Penelitianini belum pernah diteliti sebelumnya. Disini peneliti men gkaji pada persamaan aspekaspek religius kedua teks puisi "Doa" karya Amir Hamzah Dan "Doa" Sanusi Pane. Terkait dengan rumusan dan tujuan diatas, hasil penelitian ini dapat dimanfaatkan sebagai salah satu referensi atau paling tidak sebagai pelengkap berbagai literatur dalam rangka penerapan dan pengembangan teori sastra, khususnya untuk bidang kajian bandingan.

Penelitian ini diharapkan dapat memberikan manfaat bagi penulis dan

pembaca, baik manfaat secara teoritis maupun praktis. Secara teoritis hasil penelitian bermanfaat bagi perkembangan ilmu sastra, terutama dalam kajian bandingan. Secara praktis, penelitian ini bermanfaat bagi masyarakat pembaca untuk mengetahui bahwa hadirnya sebuah karya baru tidak terlepas dari refleksi zamannya.

Dalam penelitian ini menggunakan pendekatan sastra bandingan dengan menggunakan teori Hutomo yang berlandaskan diri pada 3 hal yaitu (1) Afinitas yaitu keterkaitan unsur-unsur intrinsik karya sastra (2) Tradisi yaitu unsur yang berkaitan dengan kesejarahan penciptaan karya sastra, (3) Pengaruh. Dalam penelitian ini, landasan yang paling tepat digunakan adalah landasan Afinitas, sebab aspek-aspek yang ditemukan dalam penelitian berkaitan dengan unsur instrinsik berupa persamaan 
judul, pemaknaan, dan penyebutan kepada Tuhan.

\section{KAJIAN PUSTAKA}

Teori yang digunakan dalam penelitian ini adalah teori Pemikiran Hutomoyang berlandaskan diri pada 3 hal yaitu (1) Afinitas yaitu keterkaitan unsur-unsur intrinsik karya sastra (2) Tradisi yaitu unsur yang berkaitan dengan kesejarahan penciptaan karya sastra,

Pengaruh. Dalam penelitian ini, landasan yang paling tepat digunakan adalah landasan Afinitas, sebab aspek-aspek yang ditemukan dalam penelitian berkaitan dengan unsur instrinsik berupa persamaan judul, pemaknaan, dan penyebutan kepada Tuhan.

Dalam sastra bandingan, perbedaan dan persamaan yang ada dalam sebuah karya sastra merupakan objek yang akan dibandingkan. Dalam sastra bandingan yang dibandingkan adalah kejadian sejarah, pertalian karya sastra, persamaan dan perbedaan, tema, genre, style,perangkat evolusi budaya, dan sebagainya (Remak, 1990: 13).

Bassnett (dalam Jurnal Kalam, 2004: 7) mengemukakan bahwa sastra bandingan adalah kajian interdisipliner atas teks-teks secara lintas budaya yang terfokus pada pola-pola hubungan dalam sastra yang berbeda baik yang bersifat lintas ruang maupun lintas waktu.

Menurut Damono (2005:2), sastra bandingan adalah pendekatan dalam ilmu sastra yang tidak menghasilkan teori tersendiri. Boleh dikatakan teori apa pun bisa dimanfaatkan dalam penelitian sastra bandingan, sesuai dengan obyek dan tujuan.

Bidang-bidang pokok yang menjadi titik perhatian dalam perhatian dalam penelitian sastrabandingan menurut Kasim (dalam Endraswara, 2011: 81) adalah sebagai berikut. 1. Tema dan motif, melingkupi (a) buah pikiran, (b) gambaran perwatakan, (c) alur (plot), episode, latar (setting), (d) ungkapan-ungkapan 2. Genre dan bentuk (form), stalistika, majas, suasana 3. Aliran (moventent) dan angkatan (generation)masuknya unsur-unsur lain kedalam sebuah karya4. Hubungan karya sastra dengan ilmu pengetahuan, agama/ kepercayaan, dan karya-karya seni 5. 
Teori sastra, sejarah sastra, dan teori kritik sastra

Dalam pendapat ini Kasim cukup banyak memberikan batasan dalam hal bidang apa saja yang dapat dibandingkan dalam sebuah penelitian sastra bandingan. Menurut Endraswara (2011: 163) objek berkaitan dengan muatan apa yang terdapat dalam sastra, yang dominan dan layak dibandingkan dapat terkait dengan tema, tokoh, aspek sosial, kecerdasann emosi dan sebagainya.

Dari pendapat di atas dapat disimpulkan bahwa tidak ada batasan ataupun patokan dalam objek yang dijadikan kajian dalam satra bandingan biarlah peneliti yang lebih kreatif menemukan kebaharuan. Apapun boleh dijadikan kajian yang terpenting adalah adanya kesamaan dan perbedaan diantara bahan yang dijadikan penelitian.

Dari beberapa uraian di atas, dapat disimpulkan bahwa sastraperbandingan adalah studi sastra yang membandingkan dua buah karya sastra atau lebih. Karya sastra yang diperbandingkan bisa berupa sastra tulis maupun sastra lisan.

\section{METODE}

Jenis penelitian yang digunakan dalam mengkaji puisi Doa karya Amir Hamzah dan Sanusi Pane menggunakan penelitian kualitatif. Penelitian kualitatif ini sebagai prosedur penelitian yang menghasikan data deskriptif berupa kata-kata tertulis atau lisan (Bogdan dan Taylor dalam Moleong 1994:3).

Untuk mengkaji puisi Doa karya Amir Hamzah dan Sanusi Pane diperlukan Pendekatan sastra bandingan untuk mengkaji persamaan aspek-aspek yang terkandung dalam puisi tersebut. Adapun Sumber data penelitian ini berupa puisi Doa karya Amir Hamzah dan Sanusi Pane. sumber data menurut (Arikunto, 2010:17) mengenai bagaimana data itu diperoleh. Data yang digunakan dalam penelitian ini berupa teks puisi.

Teknik pengumpulan data yang digunakan dalam penelitian ini yaitu teknik studi pustaka. Melalui dokumen terhadap pustaka-pustaka yang relevan dan ditunjang dengan jurnal, penelusuran artikel-artikel melalui internet (Sugiarti, 2014:138) 
Teknik analisis data yang digunakan dalam penelitian ini menggunakan analisis isi, karena objek yang akan dikaji berupa puisi. Dokumen tertulis dan arsip merupakan sumber data yang sering memiliki posisi penting dalam penelitian kulaitatif (Sutopo, 2002:69). Adapun langkah-langkah yang digunakan untuk menganalisis sebagai berikut: (1) membaca dan memahami puisi Doa (2) mencatat data pada objek penenlitian (3) pengelompokan data berdasarkan jenis data yang akan diteliti (4) menarik kesimpulan dan digunakan untuk keabsahan data.

Untuk mengecek keabsahan data menggunakan triangulasi. Triangulasi dilakukan sejak waktu pengumpulan data sampai analisis data. Hal ini dilakukan dengan memanfaatkan metode dan teori yang digunakan dalam penelitian, selain itu juga dilakukan dengan diskusi antar teman sejawat dan ahlinya.

\section{HASIL DAN PEMBAHASAN}

Hubunganintertekstualitas puisi "Doa" karya Sanusi Pane dengan puisi“Doa" karya Amir
Hamzah dapat dilihat sebagai berikut:

Doa

Karya Sanusi Pane

O, kekasihku, turunkan cintamu memeluk daku

Sudah bertahun aku menanti, sudah bertahun aku mencari

$\mathrm{O}$, kekasihku, turunkan rakhmat-Mu ke dalam taman hatiku

Bunga kupelihara dalam musim berganti, bunga kupelihara dengan berahi

$\mathrm{O}$, kekasihku, buat jiwaku bersinar sinar!

$\mathrm{O}$, keindahan, jiwaku rindu siang dan malam, hendak memandang cantik parasMu

Datanglah tuan dari belakang pegunungan dalam ribaan pagi tersenyum

$\mathrm{O}$, beri daku tenaga, supaya aku bisa bersama Tuan melayang sebagai garuda menuju kebiruan langit nilakandi

\section{Doa \\ karya Amir Hamzah}

Dengan apakah kubandingkan pertemuan kita, kekasihku? Dengan senja samar sepoi, pada masa purnama meningkat naik, setelah menghalaukan panas payah terik.

Angin malam menghembus lemah, menyejuk badan, melambung rasa menayang pikir, membawa angan ke bawah kursi-Mu.

Hatiku terang menerima kata-Mu, bagai bintang memasang lilin-Nya. Kalbuku terbuka menunggu kasih$\mathrm{Mu}$, bagai sedap malam menyirak kelopak.

Aduh, kekasihku, isi hatiku dengan 
kata-Mu, penuhi dadaku dengan cahayamu, biar bersinar mataku sendu, biar berbinar galakku rayu!

$$
\text { Pada dasarnya yang }
$$

menentukan ada tidaknya hubungan interteks dalam sebuah karya sastra khususnya puisi adalah pembaca itu sendiri. Dalam praktek sastra bandingan menurut Hutomo (1993: 11-12) berlandaskan diri pada 3 hal yaitu sebagai berikut.

1. Afinitas, yaitu keterkaitan unsurunsur intrinsik (unsur dalaman) karya sastra, misalnya unsur struktur, gaya, tema, mood (suasana yang terkandung dalam karya sastra) dan lain-lain, yang dijadikan bahan pelisan karya sastra.

2. Tradisi, yaitu unsur yang berkaitan dengan kesejarahan penciptaan karya sastra.

3. Pengaruh, istilah pengaruh, sebenarnya, tidak sama dengan menjimplak, plagiat, karena istilah ini sarat dengan nada negatif.

Dalam penelitian ini, landasan yang paling tepat digunakan adalah landasan Afinitas, sebab jika dilihat dari segi tema, keduanya sama-sama membahas tentang keagamaan, mereka juga menciptakan suasana yang sangat sakral dalam berdoa, begitu merindunya mereka terhadap tuhan-Nya, selain itu dari segi judul mereka memiliki kesaaman yaitu Doa.

Puisi "Doa" karya Sanusi Pane memiliki hubungan persamaan dengan puisi "Doa" karya Amir Hamzah. Persamaan tersebut dapat dilihat dari gaya penulisannya, judulnya, maknanya, dan kedua penyair tersebut juga sama-sama menyebut Tuhan dengan sebutan kekasih.

Pada dasarnya Sanusi Pane merupakan penyair Angkatan Balai Pustaka tetapi sering dikaitkan dengan Angkatan Pujangga Baru. Tetapi dalam hal ini puisi "Doa" karya Sanusi Pane diklasifikasikan kedalam Angkatan Balai Pustaka.

\section{A. Analisis puisi Doa karya Sanusi}

\section{Pane}

Puisi "Doa" karya Sanusi Pane terdiri dari satu paragraf (delapan baris) sedangkan diksi yang digunakan adalah diksi yang ringan, mudah, jelas, dan familiar dalam kehidupan sehari-hari sehingga mudah dipahami bagi pembaca. 
Dalam puisi tersebut Sanusi Pane selalu menyebut Tuhan dengan sebutan kekasih. Hal ini nampak dalam sajak /O, kekasihku, turunkan cintamu memeluk daku//O, kekasihku, turunkan rakhmat-Mu ke dalam taman hatiku//O, kekasihku, buat jiwaku bersinar sinar!//.

Dari sajak tersebut terlihat bahwa si aku selalu menyebut nama kekasih, dan kekasih di sini bukan sebagai kekasih hati atau teman hidup tetapi kekasih di sini ditujukan untuk menyebut Tuhan. Itu artinya sajak tersebut menggambarkan permohonan si aku kepada Tuhan bukan kepada kekasih.

\section{B. Analisis puisi Doa karya Amir Hamzah}

Begitu juga dengan puisi "Doa" karya Amir Hamzah terdiri dari tiga bait yangmenunjukkankesej ajarangagasan.

Sesuaidenganzamannya, Amir Hamzahmempergunakanekpresiroma ntik, yaitu dengan menyebut Tuhan dengan sebutan kekasih. Hal ini karena penyair ingin menunjukkan kemesraan hubungannya dengan Tuhan bagaikan kemesraannya dengan sang kekasih.
Hal ini dapat dilihat dalam sajak/dengan apakah kubandingkan pertemuan kita, kekasihku?//kalbuku terbuka menunggu kasih-Mu//aduh, kekasihku, isi hatiku dengan kataMu/l.

Pada puisi "Doa" karya Amir Hamzah mengandung makna waktu pertemuan antara si aku dengan kekasih (Tuhan). Artinya, si aku sebagai mahluk ciptaan-Nya dan Tuhan sebagai pencipta-Nya atau pertemuan itu dilakukan waktu shalat. Sampai-sampai waktu ini dianggap sangat berharga sehingga waktu tersebut tidak mau dilewatkan atau diabaikan.

Selanjutnya pertemuan itu dilaksanakan setelah shalat magrib menjelang isya'. Hal ini terdapat dalam sajak/ Dengan apakah kubandingkan pertemuan kita, kekasihku?//Dengan senja samar sepoi, pada masa purnama meningkat naik, setelah menghalaukan panas payah terik/. Selanjutnya dalam sajak/aduh, kekasihku, isi hatiku dengan kata$\mathrm{Mu}$, penuhi dadaku dengan cahayamu, biar bersinar mataku sendu, biar berbinar galakku rayu!/ mengandung makna permohonan si 
aku kepada Tuhan agar diberikan petunjuk berdasarkan isi yang terkandung dalam Al-Quran, supaya hati si aku merasa bahagia dan damai.

$\begin{array}{cccc}\text { Sedangkan } & \text { dalam } & \text { puisi } \\ \text { "Doa" } & \text { karya } & \text { Sanusi } & \text { Pane }\end{array}$ menggambarkan si aku yang selalu memohon kepada Tuhan agar diberikan kedamaian, ketentraman dan ketenangan hati yang sudah sekian lama dinanti. Permohonan itu selalu si aku lakukan siang dan malam tanpa kenal lelah untuk selalu sujud dan taat hanya kepada-Mu. Hal ini terdapat dalam sajak /O, kekasihku, turunkan cintamu memeluk daku//sudah bertahun aku menanti, sudah bertahun aku mencari//O, kekasihku, turunkan rakhmat-Mu ke dalam taman hatiku//O, keindahan, jiwaku rindu siang dan malam, hendak memandang cantik paras-Mu/.

Kedalaman rasa ketuhanan yang terdapat pada kedua puisi tersebut nampak dalam pemilihan kata, ungkapan, lambang, dan kiasan-kiasan yang digunakan penyair. Unsur-unsur tersebut menunjukkan betapa erat hubungan antara penyair dengan Tuhan.
Puisi tersebut juga menunjukkan keinginan penyair agar Tuhan mengisi seluruh kalbunya. Kemudian tentang besarnya cinta, kerinduan, dan kepasrahan sang penyair akan Tuhannya itu dapat kita rasakan secara nyata dalam puisi tersebut.

\section{KESIMPULAN}

Dari beberapa uraian di atas, dapat disimpulkan bahwa sastra perbandingan adalah studi sastra yang membandingkan dua buah karya sastra atau lebih. Karya sastra yang diperbandingkan bisa berupa sastra tulis maupun sastra lisan.

Meskipun judul yang dipakai sama-sama Doa, tapi penggambaran penyair terhadap Doa berbeda. Puisi Doa karya Amir Hamzah, mengandung makna waktu pertemuan antara si aku dengan kekasih (Tuhan). Artinya, si aku sebagai mahluk ciptaan-Nya dan Tuhan sebagai pencipta-Nya atau pertemuan itu dilakukan waktu shalat. Sampai-sampai waktu ini dianggap sangat berharga sehingga waktu tersebut tidak mau dilewatkan atau diabaikan.

Sementara puisi Doa karya Sanusi Pane, menggambarkan si aku 
yang selalu memohon kepada Tuhan

agar diberikan kedamaian,

ketentraman dan ketenangan hati

yang sudah sekian lama dinanti.

Permohonan itu selalu si aku lakukan

siang dan malam tanpa kenal lelah

untuk selalu sujud dan taat hanya kepada-Mu.

\section{DAFTAR PUSTAKA}

Arikunto, S. 2010. Prosedur Penelitian Suatu Pendekatan Prakltik. Jakarta: RinekaCipta.

Atmosuwito, S. (1989). Perihal Sastra dan Religiusitas dalam Sastra. Sinar Baru.

Endraswara, S. (2011). Metodelogi Penelitian Sastra Epistemologi, Model, Teori, dan Aplikasi. Yogyakarta: Caps.

Endraswara, Suwardi. Metodologi Penelitian Sastra. Yogyakarta: CAPS (Center for Academic Publishing Service).

Husin, S. Jaafar. 1995. Penelitian Sastra: Metodelogi dan Penerapan Teori. Kuala Lumpur: Dewan Bahasa dan Pustaka.

Mangunwijaya, Y.B. 1982. Sastra dan Religiositas. Jakarta: Sinar Harapan.

Moleong, Lexy $\mathrm{J}$. 1994.MetodologiPenelitianKua litatif. Bandung: RemajaRosdaKarya.

Nurgiyantoro, Burhan. (1995). Teori Pengkajian Fiksi. Yogyakarta: Gajah Mada Universitas press.
Pradopo, Rachmat Djoko.

(2009). Pengkajian Puisi.

Gajah Mada University:

YogyakartaTeeuw, A. (1984).

Satra Dan Ilmu Sastra,

Pengantar Teori Sastra. Jakarta:

Pustaka Jaya

Remak, Henry H. 1990. "Sastra

Bandingan Tarif dan

Fungsi”. Dalam Newton P.

Stallknecht dan Horst Frenz (ed)..

Sugiarti. 2014. Estetika Pada Novel Geni Jora Karya Abidah El Khalieqy. Jurnal Atavisme 17 (2)

Sutopo, H. B. 2002. Metode

Penelitian Kualitatif: Dasar Teori dan Penerapan dalam Penelitian. Surakarta: Sebelas Maret University. Yulianto, A. (2015). Analisis Intertekstual Puisi "Tangisan Batu" dan "Air Mata Legenda" karya Abdurrahman El Husainy. Sirok Bastra, 3(1), 75-81. 